\title{
Community-acquired Clostridium difficile infection: an increasing public health threat
}

This article was published in the following Dove Press journal:

Infection and Drug Resistance

17 March 2014

Number of times this article has been viewed

\section{Arjun Gupta \\ Sahil Khanna \\ Division of Gastroenterology and Hepatology, Mayo Clinic, Rochester, MN, USA}

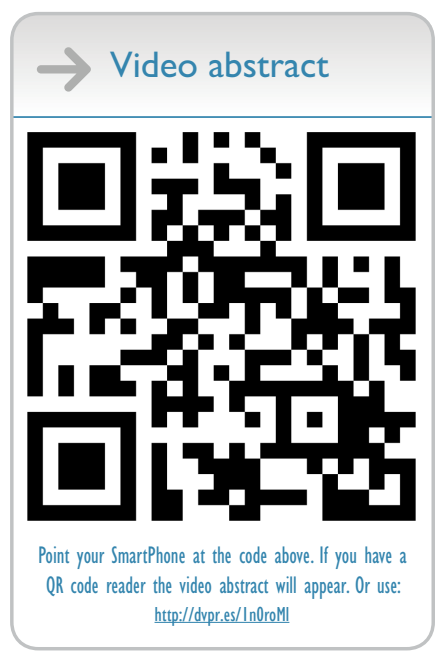

Correspondence: Sahil Khanna Division of Gastroenterology and Hepatology, 200 Ist Street SW, Rochester, MN 55905, USA

Tel +I 5072842468

Fax + I 5072840538

Email khanna.sahil@mayo.edu

\begin{abstract}
There has been a startling shift in the epidemiology of Clostridium difficile infection over the last decade worldwide, and it is now increasingly recognized as a cause of diarrhea in the community. Classically considered a hospital-acquired infection, it has now emerged in populations previously considered to be low-risk and lacking the traditional risk factors for C. difficile infection, such as increased age, hospitalization, and antibiotic exposure. Recent studies have demonstrated great genetic diversity for $C$. difficile, pointing toward diverse sources and a fluid genome. Environmental sources like food, water, and animals may play an important role in these infections, apart from the role symptomatic patients and asymptomatic carriers play in spore dispersal. Prospective strain typing using highly discriminatory techniques is a possible way to explore the suspected diverse sources of $C$. difficile infection in the community. Patients with community-acquired $C$. difficile infection do not necessarily have a good outcome and clinicians should be aware of factors that predict worse outcomes in order to prevent them. This article summarizes the emerging epidemiology, risk factors, and outcomes for community-acquired $C$. difficile infection.
\end{abstract}

Keywords: community acquired infection, Clostridium difficile, epidemiology, risk factors, outcome

\section{Introduction}

Clostridium difficile is the major cause of infectious diarrhea in hospitalized patients ${ }^{1}$ and the primary infectious cause of pseudomembranous colitis. ${ }^{2}$ Recent studies have shown increasing incidence, severity, and recurrence rates of $C$. difficile infection (CDI). ${ }^{3-9}$ It has recently surpassed methicillin-resistant Staphylococcus aureus as the most common hospital-acquired infection in the USA. ${ }^{10,11}$ However, in contrast with prior epidemiological studies, CDI is now being increasingly recognized as a cause of diarrhea in the community, especially in younger individuals and in populations lacking the traditional risk factors for CDI, such as hospitalization and antibiotic exposure. . $^{3,12-14}$ This review focuses on the epidemiology, increasing importance, novel risk factors, and outcomes for community-acquired CDI.

\section{Epidemiology of community-acquired CDI}

In 2007, the Infectious Diseases Society of America proposed guidelines for the classification of CDI to overcome the issue of multiple surveillance definitions. ${ }^{15}$ CDI is defined as: community-acquired if symptom onset occurs in the community or within 48 hours of admission to a hospital, after no hospitalization in the past 12 weeks; hospital-acquired if onset of symptoms occurs more than 48 hours after admission to or 
less than 4 weeks after discharge from a health care facility; or indeterminate if symptom onset occurs in the community between 4 and 12 weeks after discharge from a hospital. ${ }^{15,16}$ A study from the Cleveland Clinic (Cleveland, OH, USA) compared two different definitions of community-acquired CDI and showed concordance in only $71 \%$ of cases. ${ }^{17}$ Using different definitions, the percentage of community-acquired CDI varied from $10 \%$ to $37 \%$ of the total cases in another study. ${ }^{18}$ These studies have highlighted the need to use a standard definition to distinguish between hospital-acquired CDI and community-acquired CDI.

The incidence of CDI was relatively stable until the mid-to-late 1990s, after which its epidemiology changed dramatically. Since 2000, there have been several reports of an increase in the incidence and severity of CDI, $, 7,11,19-23$ with CDI being increasingly recognized in the community. ${ }^{3,13,24-28}$ Community-acquired CDI was likely previously underdiagnosed owing to a lack of awareness of CDI outside the hospital setting. Data from North America and Europe suggest that $20 \%-27 \%$ of all CDI cases are community-associated, with an incidence of 20-30 per 100,000 population. ${ }^{3,13,29,30}$ In a population-based US study, $41 \%$ of the 385 definite CDI cases were community-acquired; the overall incidence of community-acquired and hospital-acquired CDI increased by 5.3-fold and 19.3-fold, respectively, over the study period. ${ }^{12}$ In both this and another study, ${ }^{31}$ patients with communityacquired infection were younger compared with those with hospital-acquired infection (median age 50 years versus 72 years), more likely to be female (76\% versus $60 \%$ ), had lower comorbidity scores, and were less likely to have severe infection $(20 \%$ versus $31 \%){ }^{12}$

\section{Traditional risk factors may be absent in community-acquired CDI}

Community-acquired CDI has been described in populations previously considered to be at low risk, including healthy peripartum women, children and young adults, antibiotic-naïve patients, and those with no recent health care exposure. ${ }^{3,13,32,33}$

\section{Antibiotic exposure}

Exposure to antimicrobial agents is recognized as the most important risk factor for CDI. ${ }^{34} \mathrm{~A}$ recent study by Dial et al determined that as many as $45.7 \%$ of patients with CDI had no prior exposure to antibiotics in the 90-day period before the onset of CDI. ${ }^{35}$ In another case-control study, $52 \%$ of patients had no antibiotic exposure in the 4 -week time period prior to CDI onset. ${ }^{13}$ A population-based cohort study from the Mayo Clinic, Rochester, MN, USA, showed that patients with community-acquired CDI were less likely to have been exposed to antibiotics when compared with those having hospital-acquired CDI (78\% versus 94\%). ${ }^{12}$ A case-control study demonstrated that, although patients with community-acquired CDI were more likely to have had antibiotic exposure compared with healthy controls, $27 \%$ of cases did not receive antibiotics in the 6 months prior to infection. ${ }^{36}$ A recent large epidemiological study using active surveillance showed that more than a third of patients with community-acquired CDI did not receive antibiotics in the 12 weeks prior to infection. ${ }^{37}$ These results indicate that although antimicrobial use remains a risk factor for CDI in the community, it may not be as important for hospital-acquired CDI. The risk of developing community-acquired CDI may also be affected by the antimicrobial agent administered, with two recent meta-analyses indicating that exposure to clindamycin, fluoroquinolones, and beta lactams/beta lactamase inhibitors conferred much greater risk of communityacquired CDI compared with macrolides, sulfonamides, and penicillins. ${ }^{38,39}$

\section{Age}

Although increasing age is a well recognized risk factor for CDI, studies have consistently shown that case patients with community-acquired CDI were younger than those with hospital-acquired CDI. ${ }^{12,40}$ In a population-based study from Olmsted County, MN, USA, patients with community-acquired CDI were younger than those with hospital-acquired CDI (median age 50 years versus 72 years) and more likely to be female $(76 \%$ versus $60 \%) .{ }^{12}$ A recent, large, population-based study with active surveillance for community-acquired CDI revealed a median patient age of 51 years. ${ }^{37}$ An epidemiological study from the UK showed that almost all community-acquired CDI cases occurred in patients younger than 65 years of age. ${ }^{41}$ In contrast, almost one third of patients with community-acquired CDI in another cohort were elderly (aged $>65$ years), similar to findings in another investigation where almost a half of patients with community-acquired CDI were elderly. ${ }^{31}$ These findings suggest that although patients with community-acquired CDI are younger than those with hospital-acquired CDI, communityacquired CDI occurs among all age groups in the community. There has been increasing evidence of community-acquired CDI affecting the pediatric population, traditionally thought to be at low risk for CDI, with a population-based cohort study from the Mayo Clinic, showing a striking increase in CDI in the pediatric population over the last 20 years, 
especially in the community setting and in infants, ${ }^{42}$ while other studies have reported an increase in pediatric CDI presenting to the outpatient setting ${ }^{43}$ and the emergency room. ${ }^{44}$ The role of asymptomatically colonized infants in the spread of community-acquired CDI is discussed below.

\section{Gastric acid suppression}

The role of gastric acid suppression in CDI remains controversial. There is conflicting evidence as to whether stomach acid kills $C$. difficile spores. ${ }^{45,46}$ Proton pump inhibitors (PPIs) may also affect the microbiota of the stomach and the large intestine. ${ }^{47}$ Recent data have suggested that circumventing the potentially protective effect of stomach acid, for example through the use of post-pyloric enteral feeding or the use of PPIs or histamine-2 receptor blockers, may lead to a two to three-fold increased risk of acquisition of CDI. ${ }^{25,48}$ Two recent meta-analyses concluded that PPI use is associated with 1.69-1.74 times the odds of CDI relative to no PPI use. ${ }^{49,50}$ Some other studies have shown that after controlling for important confounders, use of PPIs and histamine-2 receptor blockers was not associated with the risk of CDI,${ }^{51}$ or adverse outcomes from CDI. ${ }^{52}$ Thus, it is not clear whether use of acid-suppressing drugs is an independent risk factor for CDI, although the US Food and Drug Administration has recently issued a warning that PPIs are associated with an increased risk of CDI. Hospital-acquired CDI and community-acquired CDI may differ in their relationship to PPI use owing to differences in circulating Clostridial strains and the differential antibiotic exposure in the two settings. ${ }^{53}$ There was a trend toward higher PPI use in antibiotic-naïve patients with community-acquired CDI when compared with patients with community-acquired CDI and antibiotic exposure. ${ }^{37} \mathrm{~A}$ retrospective review demonstrated a clinically relevant interaction between antibiotic and PPI use in hospitalized patients with CDI, with patients receiving a single antibiotic being more than five times more likely to be exposed to PPIs when compared to patients receiving five or more antibiotics. ${ }^{54}$

\section{Comorbid conditions}

Additional potential risk factors for CDI that have been identified include a higher number of comorbid conditions, ie, chronic kidney disease, inflammatory bowel disease, immunodeficiency including human immunodeficiency virus (HIV) infection, hypoalbuminemia, malignant lesions, solid organ transplant, and use of chemotherapeutic agents. ${ }^{55-58}$ These patients are at increased risk of CDI not only due to their underlying disease, but also their frequent prolonged hospitalizations and broad-spectrum antimicrobial use. As care shifts closer to the home and these patients experience more outpatient health care, it will not be surprising if we observe increasing community-acquired CDI in these patient populations.

Reduced microbial diversity in the gut is a common pathogenic pathway for inflammatory bowel disease and CDI ${ }^{59}$ Patients with inflammatory bowel disease, especially those with colonic involvement, have long been known to have increased CDI rates and disproportionately higher morbidity and mortality compared with CDI patients without inflammatory bowel disease. ${ }^{55,57,60,61}$ Multiple reasons probably account for this, including older age, medications (immunosuppressives/antibiotics), and hospitalization. In retrospective population studies of both adults and children, patients with inflammatory bowel disease and CDI were younger and more often had acquired infections as outpatients compared with patients without inflammatory bowel disease and with CDI. ${ }^{60,62,63}$

Chronic kidney disease has been associated with increased risk of CDI in several studies, ${ }^{64,65}$ although some found increased risk only in patients undergoing dialysis. ${ }^{66}$ Concomitant acute kidney injury predicts a worse outcome in CDI, ${ }^{67}$ which is in line with the Infectious Diseases Society of America guidelines that the presence of acute kidney injury is a marker of CDI disease severity. ${ }^{16}$

Steroid initiation has been shown to increase CDI risk three times over other immunomodulator agents in patients with inflammatory bowel disease independent of dose and treatment duration, ${ }^{68}$ and steroid use has been shown to increase short-term mortality in hospitalized patients with CDI ${ }^{69}$ High-dose corticosteroid use has also been associated with an increased risk of CDI relapse in solid organ transplant patients. ${ }^{70}$ Data on risk of CDI with other immunomodulatory medications is more controversial, with some studies failing to find an association ${ }^{68,71}$ and others showing increased risk. ${ }^{60,72} C$. difficile has been recognized as the most common cause of bacterial diarrhea in HIV patients, although rates of CDI have reduced in the HIV population after initiation of antiretroviral therapy, so not mirroring the global trend of increased CDI burden. ${ }^{73}$

Several early studies have shown an increased risk of CDI in the transplant population, although infection did not seem to have a worse outcome in hematopoietic stem cell transplant patients, and most patients responded well to standard CDI therapy. ${ }^{74-77}$ No significant difference was found with regard to disease severity in solid organ transplant recipients and controls. ${ }^{70} \mathrm{~A}$ recent, nested, retrospective, 
case-control study demonstrated a high rate of CDI in hematopoietic stem cell transplant recipients, with prior chemotherapy, broad-spectrum antimicrobial use, and vancomycin-resistant enterococci colonization recognized as risk factors. ${ }^{78}$ Similar risk factors were observed in a retrospective study in kidney transplant recipients. ${ }^{79}$ The onset to CDI in autologous hematopoietic stem cell transplant recipients and kidney transplant recipients has been found to be less than a week. ${ }^{74,78,79}$ This supports the hypothesis that CDI is not always nosocomially acquired, even when it presents in the hospital setting, and patients may have been colonized earlier, even in the community setting.

\section{Sources and transmission of community-acquired CDI}

The primary means of transmission of CDI is believed to be from environment-to-person or person-to-person via the fecal-oral route. The organism is ingested either as the vegetative form or as spores (which survive for longer periods in the environment and are able to endure acidic stomach $\mathrm{pH})$. Antimicrobial drugs alter the protective gut microbiome by decreasing bacterial diversity and create a favorable microenvironment for $C$. difficile to colonize and proliferate. Patients with diarrhea secondary to CDI shed spores into the environment and may be considered as a primary source of spreading infection. ${ }^{80}$ Infection control guidelines strongly recommend strict isolation of these patients when inpatients, in order to limit person-to-person transmission via health care personnel or the environment. ${ }^{81-83}$ Despite implementation of infection control practices, there is an increasing incidence of community-acquired CDI, which suggests alternate sources of infection and modes of transmission in the community. Assorted sources may be playing a role in $C$. difficile transmission alongside symptomatic patients. Using whole genome sequencing of more than 1,200 C. difficile isolates from the health care and community setting, a study based in Oxfordshire, UK, demonstrated that $45 \%$ of all isolates were genetically distinct from all previously tested isolates. ${ }^{84}$ The genetically diverse nature of these isolates suggests the existence of other important sources of infection apart from symptomatic patients. These possible novel factors are discussed below.

\section{Novel and established risk factors}

The factors responsible for the emergence of CDI in the community include increasing outpatient antibiotic prescriptions, greater use of acid-suppression medications, an increase in the proportion of asymptomatic carriers in the community leading to an increase in person-to-person transmission, novel risk factors like food and water contamination, and the epidemic $C$. difficile strain. ${ }^{3,85-87}$ Higher clinician awareness of CDI as a possible explanation of diarrhea in the community probably also contributes to the increased incidence via an increase in the number of stool tests for $C$. difficile performed in patients with diarrhea.

\section{Role of asymptomatic carriers}

Colonization of healthy nonhospitalized adults is uncommon, but colonization rates among hospitalized patients are much higher, ranging from $25 \%$ to $55 \%{ }^{88,89}$ In the context of a $C$. difficile infection outbreak in a long-term care facility, a study from Cleveland, $\mathrm{OH}$, USA, found that more than half of asymptomatic residents were fecal carriers of toxigenic $C$. difficile strains, more than a third of which were epidemic North American pulse-field type 1 (NAP1) strains. Asymptomatic carriers outnumbered CDI patients seven to one during this study. Previous CDI and recent antibiotic use were found to predict asymptomatic carriage. Skin and environmental surface contamination in asymptomatic carriers was nearly as high as in CDI patients, and spores were also recovered from the study investigators' hands. These findings suggest that asymptomatic carriers contribute significantly to CDI transmission in long-term care facilities, and may have a role in dissemination of $C$. difficile in the community as well. ${ }^{88}$ High rates of internally acquired $C$. difficile colonization and CDI have been reported inside long-term care facilities, ${ }^{90}$ and a recent study from Scotland showed increased CDI rates among care home residents older than 65 years of age when compared with controls residing at home. ${ }^{91}$ A case-control study identified close contact with infants under the age of 2 years as a potential risk factor for community-acquired CDI. ${ }^{13}$ A plausible role for infants and young children acting as reservoirs and vectors for $C$. difficile is supported by data showing that several toxigenic and nontoxigenic strains are carried by infants, although none were found to carry the hypervirulent 027 or 078 strains. $^{92,93}$ Regular diaper changing of babies carrying $C$. difficile by mothers has been hypothesized to explain the female predilection of community-acquired CDI. ${ }^{94}$

\section{Role of outpatient health care exposure}

Exposure to $C$. difficile in outpatient settings may provide a possible link in the chain between nosocomial CDI and community-acquired CDI. More than $80 \%$ of CDI patients discharged from hospital had an outpatient clinic visit within 12 weeks of discharge in one study, ${ }^{95}$ and CDI patients have 
been known to shed spores even after completion of therapy. ${ }^{96}$ Health care exposure in outpatient settings (physicians' offices, emergency departments, dialysis facilities) is a potential risk factor for community-acquired CDI, with a recent large study showing that more than two thirds of patients with communityacquired CDI without inpatient hospital exposure had lowlevel exposure in the preceding 12 weeks. ${ }^{37}$

\section{Role of food and animals}

Given the genetic diversity in $C$. difficile isolates, the isolation of $C$. difficile in food and animals, the similarities in strains isolated from animals and humans, and the absence of traditional risk factors in a large subset of patients with community-acquired CDI, there is mounting concern over food-borne and zoonotic spread of $C$. difficile in the community. ${ }^{97-99}$ A recent study showed that $C$. difficile spores survived the $71^{\circ} \mathrm{C}$ temperature recommended for cooking ground meats. ${ }^{100} \mathrm{C}$. difficile carriage has also been reported in many animal species, including cattle and pigs; these may be a potential reservoir for clinically relevant strains eventually causing CDI in humans. ${ }^{101-107}$ There have been several recent studies identifying $C$. difficile strains in retail meat products, including beef, chicken, and pork, ${ }^{102,108,109}$ and similarities between strains isolated from animal feed and those reported to cause CDI in humans. ${ }^{98,99,102,105}$ C. difficile ribotype 078 was originally identified as the predominant strain in swine and cattle, and is now increasingly identified in human CDI as causing severe disease and increased mortality, especially in the community setting. ${ }^{110}$ Animal and human strains of ribotype 078 are almost clonal, indicating that isolates had a common ancestry and porcine to human transmission is a possibility. ${ }^{98,111}$ These findings are also supported by the fact that ribotype 078 was the predominant type found in retail meat as well. ${ }^{109}$ However, in a recent study, the most common strain isolated was NAP1, while less than $7 \%$ of culture-positive isolates from community-acquired CDI patients were NAP7 or NAP8, which are the more common strains found in food and animals. ${ }^{37,108}$ There is currently no strong objective evidence to classify $C$. difficile as a foodborne or zoonotic illness. Laboratory contamination of meat samples and circulation of clonal $C$. difficile isolates among animals may contribute to the identical genotypes often seen, and strict discriminatory typing may be the only way to clarify this issue. ${ }^{112}$

\section{Emergence of new strains}

A hypervirulent $C$. difficile strain belonging to a specific type (ribotype 27/protein profile NAP1) was identified in 2005 in several CDI outbreaks all over the world, including the USA. ${ }^{5,6,113-118}$ It is identified by polymerase chain reaction (PCR) as ribotype 27 , by pulsed-field gel electrophoresis as NAP1 and by restriction-endonuclease analysis as group BI, leading to its nomenclature as BI/NAP1 or NAP1/027. ${ }^{6}$ It is also classified as toxinotype III by restriction fragment length polymorphism PCR of the toxin genes. The increased virulence of this strain may be related to the production of toxin early in infection and markedly increased toxin production (16-23 times more than other strains). ${ }^{9}$ Asymptomatic carriage of the hypervirulent strain has been linked to transmission in long-term care facilities ${ }^{88}$ Although some regions are starting to see a decrease in the prevalence of this strain, ${ }^{119,120}$ it is likely that other epidemic strains of $C$. difficile may emerge. There has also been increased focus on PCR ribotype 078 in the past decade owing to its hypervirulence and clonal presence in pigs and humans. Community-associated disease was more common among ribotype 078-infected cases, and affected patients were younger when compared with those having the 027 strain. ${ }^{110}$ Recent reports have corroborated the fear that new strains are emerging with non-027 and non-078 "hypervirulent" strains causing severe infection in both the community and hospital settings. ${ }^{121,122}$ Newer nontypical strains now account for a majority of infections in the community setting. ${ }^{123}$ The molecular epidemiology of $C$. difficile is both diverse and dynamic, ${ }^{124}$ with some strains causing large clusters during certain periods and then becoming endemic. The genetic diversity of this organism likely contributes to it being able to establish infection and cause epidemics.

\section{Molecular typing of community- acquired $\mathrm{CDI}$ isolates}

Typing is an essential tool to identify and characterize C. difficile isolates. There are various methods currently adapted globally to type $C$. difficile isolates, including pulsed-field gel electrophoresis, PCR ribotyping, toxinotyping based on restriction fragment length polymorphism, restriction endonuclease analysis, multilocus variablenumber tandem-repeat analysis, multilocus sequence typing, amplified fragment length polymorphism, and surface layer protein A gene sequence typing. ${ }^{125}$ Different methods are used across the globe, with PCR ribotyping and pulsedfield gel electrophoresis more frequently used in Europe and North America, respectively. ${ }^{126}$ A uniform worldwide method to type strains would be more ideal. Multilocus variable-number tandem-repeat analysis ${ }^{127}$ and whole genome sequencing ${ }^{128}$ both offer increased discrimination 
over other typing schemes, and have reported very similar findings despite the fact that they analyzed different parts of the bacterial genome. ${ }^{129}$

Specific $C$. difficile genotypes have been recognized to predict outcomes in CDI. Walker et al recently demonstrated that strain-specific inflammatory pathways may contribute to increased severity of illness in PCR ribotypes 027 and $078 .{ }^{130}$ Increased toxin production was primarily thought to be responsible for their "hypervirulent" behavior. ${ }^{9}$ However, no single factor can fully explain the increased virulence of C. difficile strains, and differences in toxins, sporulation, drug resistance, and cell surface proteins all play a role. ${ }^{131}$

Typing studies have demonstrated that communityacquired CDI strains have a diverse molecular epidemiology, with similarities to and differences from hospital-acquired CDI strains. ${ }^{26,40,132}$ Some studies indicate that ribotype 027 is associated with community-acquired CDI more than hospital-acquired CDI and others have reported that ribotype 027 accounts for more cases of hospital-acquired CDI, 9,123,133 whereas a large surveillance study showed that similar percentages of community-acquired CDI and hospital-acquired CDI patients were infected with the NAP1 epidemic strain. ${ }^{40}$ NAP1/toxinotype (TOX) 3 and NAP1/TOX 5 were the most common types isolated from 89 community-acquired CDI samples in one study, whereas TOX 0 strains have historically been most common in nosocomial CDI. ${ }^{134,135}$

Similarities in strain distribution in the community and hospital settings indicate that $C$. difficile may move easily from either setting to the other and common reservoirs may exist. Long-term care facilities and outpatient facilities may both be important for transfer of isolates between inpatient health care facilities and the community. Reports have also shown the preponderance of several PCR ribotypes in community-acquired CDI not often seen in the hospital epidemic setting. ${ }^{123,136}$ This argues against the presence of a direct link between nosocomial outbreaks and community onset cases. These results indicate that communityacquired CDI isolates have extremely diverse genomes, and multiple transmission routes and sources for infection probably exist.

\section{Outcomes of community- acquired CDI}

Recent reports indicate a significant increase in severe cases, colectomies, and deaths related to CDI. ${ }^{20}$ Identifying patients who are at high risk for severe CDI early in the course of infection may direct therapy and help to improve outcomes. Severe disease in the hospital has been associated with increasing age, presence of the hypervirulent strain, elevated white cell count, hypoalbuminemia, and elevated creatinine. . $^{5,51,137-140}$

Although community-acquired CDI has generally been characterized as a mild illness, it can be associated with complications and poor outcomes, including hospitalization and severe CDI. In a study of patients with community-acquired CDI at the Mayo Clinic, 40\% required hospitalization, $20 \%$ had severe infection, $4.4 \%$ had severe complicated infection, $20 \%$ had treatment failure, and $28 \%$ had recurrent CDI. ${ }^{141}$ Increasing age was a predictor of need for hospitalization, severe infection, severe complicated infection, and treatment failure, but not recurrence. Higher Charlson Comorbidity Index scores predicted the need for hospitalization and severe complicated infection, but not other outcomes. Patients who required hospitalization were older, had higher comorbidity scores, and had a higher incidence of severe infection than those who were treated in the community. The need for hospitalization has a tremendous impact on health care costs and patient outcomes. Hospitalization inadvertently exposes patients to other risks and avoidable complications, including venous thrombosis and other hospital-acquired infections. Therefore, patients with community-acquired CDI who are older or who have higher comorbidities, as well as those who meet the current definition of severe infection (based on white blood cell count or rising creatinine), should be monitored closely and managed more aggressively in the community to prevent poor outcomes.

\section{Conclusion}

The incidence of community-acquired CDI has increased significantly over the past decade. Utilizing only hospital data likely underestimates the burden of CDI. Communityacquired CDI accounts for a significant proportion of total CDI and is increasingly being recognized as an important health threat. Community-acquired CDI can affect younger patients lacking the traditional risk factors like antibiotic exposure, prior hospitalization, or age. The absence of these risk factors is not enough to exclude CDI, and testing for CDI must be considered in all patients with acute diarrhea.

Environmental sources like food, water, animals, and pets may play an important role in these infections, apart from the role symptomatic patients and asymptomatic carriers play in spore dispersal. Prospective strain typing is a possible way to explore the suspected diverse sources of CDI in the community and the genetic diversity of this organism. However, strain typing is not widely available, and currently treatment 
recommendations do not differ according to $C$. difficile strain. Without belittling the inpatient infection control measures in place, we require additional studies to identify $C$. difficile sources in the community, and determine measures to control this infection outside the hospital. Patients with communityacquired CDI do not necessarily have a good outcome, with a large proportion requiring hospitalization. Given the additional risks and costs associated with hospitalization, clinicians should be aware of factors that predict a need for hospitalization in these patients, which might lead to more intensive therapy and monitoring.

\section{Disclosure}

The authors report no conflicts of interest in this work.

\section{References}

1. Kelly CP, LaMont JT. Clostridium difficile - more difficult than ever. N Engl J Med. 2008;359(18):1932-1940.

2. Bartlett JG, Chang TW, Gurwith M, Gorbach SL, Onderdonk AB. Antibiotic-associated pseudomembranous colitis due to toxin-producing clostridia. N Engl J Med. 1978;298(10):531-534.

3. [No authors listed]. Severe Clostridium difficile-associated disease in populations previously at low risk - four states, 2005. MMWR Morb Mortal Wkly Rep. 2005;54(47):1201-1205.

4. Khanna S, Pardi DS. The growing incidence and severity of Clostridium difficile infection in inpatient and outpatient settings. Expert Rev Gastroenterol Hepatol. 2010;4(4):409-416.

5. Loo VG, Poirier L, Miller MA, et al. A predominantly clonal multiinstitutional outbreak of Clostridium difficile-associated diarrhea with high morbidity and mortality. $N$ Engl J Med. 2005;353(23):2442-2449.

6. McDonald LC, Killgore GE, Thompson A, et al. An epidemic, toxin gene-variant strain of Clostridium difficile. N Engl J Med. 2005;353(23): 2433-2441.

7. Muto CA, Pokrywka M, Shutt K, et al. A large outbreak of Clostridium difficile-associated disease with an unexpected proportion of deaths and colectomies at a teaching hospital following increased fluoroquinolone use. Infect Control Hosp Epidemiol. 2005;26(3):273-280.

8. Pepin J, Alary ME, Valiquette L, et al. Increasing risk of relapse after treatment of Clostridium difficile colitis in Quebec, Canada. Clin Infect Dis. 2005;40(11):1591-1597.

9. Warny M, Pepin J, Fang A, et al. Toxin production by an emerging strain of Clostridium difficile associated with outbreaks of severe disease in North America and Europe. Lancet. 2005;366(9491):1079-1084.

10. Miller BA, Chen LF, Sexton DJ, Anderson DJ. Comparison of the burdens of hospital-onset, healthcare facility-associated Clostridium difficile infection and of healthcare-associated infection due to methicillin-resistant Staphylococcus aureus in community hospitals Infect Control Hosp Epidemiol. 2011;32(4):387-390.

11. Zilberberg MD, Shorr AF, Kollef MH. Growth and geographic variation in hospitalizations with resistant infections, United States, 2000-2005. Emerg Infect Dis. 2008;14(11):1756-1758.

12. Khanna S, Pardi DS, Aronson SL, et al. The epidemiology of community-acquired Clostridium difficile infection: a population-based study. Am J Gastroenterol. 2012;107(1):89-95.

13. Wilcox MH, Mooney L, Bendall R, Settle CD, Fawley WN. A case-control study of community-associated Clostridium difficile infection. J Antimicrob Chemother. 2008;62(2):388-396.

14. Bauer MP, Goorhuis A, Koster T, et al. Community-onset Clostridium difficile-associated diarrhoea not associated with antibiotic usage - two case reports with review of the changing epidemiology of Clostridium difficile-associated diarrhoea. Neth J Med. 2008;66(5):207-211.
15. McDonald LC, Coignard B, Dubberke E, et al. Recommendations for surveillance of Clostridium difficile-associated disease. Infect Control Hosp Epidemiol. 2007;28(2):140-145.

16. Cohen SH, Gerding DN, Johnson S, et al. Clinical practice guidelines for Clostridium difficile infection in adults: 2010 update by the society for healthcare epidemiology of America (SHEA) and the Infectious Diseases Society of America (IDSA). Infect Control Hosp Epidemiol. 2010;31(5):431-455.

17. Fraser TG, Fatica C, Gordon SM. Necessary but not sufficient: a comparison of surveillance definitions of Clostridium difficile-associated diarrhea. Infect Control Hosp Epidemiol. 2009;30(4):377-379.

18. Shears P, Prtak L, Duckworth R. Hospital-based epidemiology: a strategy for 'dealing with Clostridium difficile'. J Hosp Infect. 2010;74(4):319-325.

19. Campbell RJ, Giljahn L, Machesky K, et al. Clostridium difficile infection in Ohio hospitals and nursing homes during 2006. Infect Control Hosp Epidemiol. 2009;30(6):526-533.

20. Dallal RM, Harbrecht BG, Boujoukas AJ, et al. Fulminant Clostridium difficile: an underappreciated and increasing cause of death and complications. Ann Surg. 2002;235(3):363-372.

21. Zilberberg MD. Clostridium difficile-related hospitalizations among US adults, 2006. Emerg Infect Dis. 2009;15(1):122-124.

22. McDonald LC, Owings M, Jernigan DB. Clostridium difficile infection in patients discharged from US short-stay hospitals, 1996-2003. Emerg Infect Dis. 2006;12(3):409-415.

23. Pepin J, Valiquette L, Cossette B. Mortality attributable to nosocomial Clostridium difficile-associated disease during an epidemic caused by a hypervirulent strain in Quebec. CMAJ. 2005;173(9):1037-1042.

24. McFarland LV, Clarridge JE, Beneda HW, Raugi GJ. Fluoroquinolone use and risk factors for Clostridium difficile-associated disease within a Veterans Administration health care system. Clin Infect Dis. 2007;45(9): 1141-1151.

25. Dial S, Delaney JA, Barkun AN, Suissa S. Use of gastric acidsuppressive agents and the risk of community-acquired Clostridium difficile-associated disease. JAMA. 2005;294(23):2989-2995.

26. Noren T, Akerlund T, Back E, et al. Molecular epidemiology of hospitalassociated and community-acquired Clostridium difficile infection in a Swedish county. J Clin Microbiol. 2004;42(8):3635-3643.

27. Beaugerie L, Flahault A, Barbut F, et al. Antibiotic-associated diarrhoea and Clostridium difficile in the community. Aliment Pharmacol Ther. 2003;17(7):905-912.

28. Frost F, Hurley JS, Petersen HV, Casciano RN. Estimated incidence of Clostridium difficile infection. Emerg Infect Dis. 1999;5(2): 303-304.

29. Kutty PK, Woods CW, Sena AC, et al. Risk factors for and estimated incidence of community-associated Clostridium difficile infection, North Carolina, USA. Emerg Infect Dis. 2010;16(2):197-204.

30. Lambert PJ, Dyck M, Thompson LH, Hammond GW. Population-based surveillance of Clostridium difficile infection in Manitoba, Canada, by using interim surveillance definitions. Infect Control Hosp Epidemiol. 2009;30(10):945-951.

31. Naggie S, Miller BA, Zuzak KB, et al. A case-control study of community-associated Clostridium difficile infection: no role for proton pump inhibitors. Am J Med. 2011;124(3):276. e271-e277.

32. Kim J, Smathers SA, Prasad P, Leckerman KH, Coffin S, Zaoutis T. Epidemiological features of Clostridium difficile-associated disease among inpatients at children's hospitals in the United States, 2001-2006. Pediatrics. 2008;122(6):1266-1270.

33. [No authors listed]. Surveillance for community-associated Clostridium difficile - Connecticut, 2006. MMWR Morb Mortal Wkly Rep. 2008;57(13):340-343.

34. Morris AM, Jobe BA, Stoney M, Sheppard BC, Deveney CW, Deveney KE. Clostridium difficile colitis: an increasingly aggressive iatrogenic disease? Arch Surg. 2002;137(10):1096-1100.

35. Dial S, Kezouh A, Dascal A, Barkun A, Suissa S. Patterns of antibiotic use and risk of hospital admission because of Clostridium difficile infection. CMAJ. 2008;179(8):767-772. 
36. Kuntz JL, Chrischilles EA, Pendergast JF, Herwaldt LA, Polgreen PM. Incidence of and risk factors for community-associated Clostridium difficile infection: a nested case-control study. BMC Infect Dis. 2011;11:194.

37. Chitnis AS, Holzbauer SM, Belflower RM, et al. Epidemiology of community-associated Clostridium difficile infection, 2009 through 2011. JAMA Intern Med. 2013;173(14):1359-1367.

38. Deshpande A, Pasupuleti V, Thota P, et al. Community-associated Clostridium difficile infection and antibiotics: a meta-analysis. J Antimicrob Chemother. 2013;68(9):1951-1961.

39. Brown KA, Khanafer N, Daneman N, Fisman DN. Meta-analysis of antibiotics and the risk of community-associated Clostridium difficile infection. Antimicrob Agents Chemother. 2013;57(5):2326-2332.

40. Dumyati G, Stevens V, Hannett GE, et al. Community-associated Clostridium difficile infections, Monroe County, New York, USA. Emerg Infect Dis. 2012;18(3):392-400.

41. Fellmeth G, Yarlagadda S, Iyer S. Epidemiology of community-onset Clostridium difficile infection in a community in the South of England. J Infect Public Health. 2010;3(3):118-123.

42. Khanna S, Baddour LM, Huskins WC, et al. The epidemiology of Clostridium difficile infection in children: a population-based study. Clin Infect Dis. 2013;56(10):1401-1406.

43. Baker SS, Faden H, Sayej W, Patel R, Baker RD. Increasing incidence of community-associated atypical Clostridium difficile disease in children. Clin Pediatr (Phila). 2010;49(7):644-647.

44. Benson L, Song X, Campos J, Singh N. Changing epidemiology of Clostridium difficile-associated disease in children. Infect Control Hosp Epidemiol. 2007;28(11):1233-1235.

45. Rao A, Jump RL, Pultz NJ, Pultz MJ, Donskey CJ. In vitro killing of nosocomial pathogens by acid and acidified nitrite. Antimicrob Agents Chemother. 2006;50(11):3901-3904.

46. Wilson KH, Sheagren JN, Freter R. Population dynamics of ingested Clostridium difficile in the gastrointestinal tract of the Syrian hamster. J Infect Dis. 1985;151(2):355-361.

47. Williams C. Occurrence and significance of gastric colonization during acid-inhibitory therapy. Best Practice Res Clin Gastroenterol. 2001;15(3):511-521.

48. Dial S, Delaney JA, Schneider V, Suissa S. Proton pump inhibitor use and risk of community-acquired Clostridium difficile-associated disease defined by prescription for oral vancomycin therapy. CMAJ. 2006;175(7):745-748.

49. Janarthanan S, Ditah I, Adler DG, Ehrinpreis MN. Clostridium difficileassociated diarrhea and proton pump inhibitor therapy: a meta-analysis. Am J Gastroenterol. 2012;107(7):1001-1010.

50. Kwok CS, Arthur AK, Anibueze CI, Singh S, Cavallazzi R, Loke YK. Risk of Clostridium difficile infection with acid suppressing drugs and antibiotics: meta-analysis. Am J Gastroenterol. 2012;107(7): 1011-1019.

51. Pepin J, Saheb N, Coulombe MA, et al. Emergence of fluoroquinolones as the predominant risk factor for Clostridium difficile-associated diarrhea: a cohort study during an epidemic in Quebec. Clin Infect Dis. 2005;41(9):1254-1260.

52. Khanna S, Aronson SL, Kammer PP, Baddour LM, Pardi DS. Gastric acid suppression and outcomes in Clostridium difficile infection: a population-based study. Mayo Clin Proc. 2012;87(7):636-642.

53. Freedberg DE, Abrams JA. Clostridium difficile infection in the community: are proton pump inhibitors to blame? World J Gastroenterol. 2013;19(40):6710-6713.

54. Stevens V, Dumyati G, Brown J, Wijngaarden E. Differential risk of Clostridium difficile infection with proton pump inhibitor use by level of antibiotic exposure. Pharmacoepidemiol Drug Saf. 2011;20(10): $1035-1042$.

55. Khanna S, Pardi DS. IBD: poor outcomes after Clostridium difficile infection in IBD. Nat Rev Gastroenterol Hepatol. 2012;9(6):307-308.

56. Patriarchi F, Rolla M, Maccioni F, et al. Clostridium difficile-related pancolitis in lung-transplanted patients with cystic fibrosis. Clin Transplant. 2011;25(1):E46-E51.
57. Ananthakrishnan AN, McGinley EL, Binion DG. Excess hospitalisation burden associated with Clostridium difficile in patients with inflammatory bowel disease. Gut. 2008;57(2):205-210.

58. Kyne L, Sougioultzis S, McFarland LV, Kelly CP. Underlying disease severity as a major risk factor for nosocomial Clostridium difficile diarrhea. Infect Control Hosp Epidemiol. 2002;23(11):653-659.

59. Khanna S, Tosh PK. A clinician's primer on the role of the microbiome in human health and disease. Mayo Clin Proc. 2014;89(1):107-114.

60. Issa M, Vijayapal A, Graham MB, et al. Impact of Clostridium difficile on inflammatory bowel disease. Clin Gastroenterol Hepatol. 2007;5(3):345-351.

61. Rodemann JF, Dubberke ER, Reske KA, Seo da H, Stone CD. Incidence of Clostridium difficile infection in inflammatory bowel disease. Clin Gastroenterol Hepatol. 2007;5(3):339-344.

62. Issa M, Ananthakrishnan AN, Binion DG. Clostridium difficile and inflammatory bowel disease. Inflamm Bowel Dis. 2008;14(10): $1432-1442$.

63. Kelsen JR, Kim J, Latta D, et al. Recurrence rate of clostridium difficile infection in hospitalized pediatric patients with inflammatory bowel disease. Inflamm Bowel Dis. 2011;17(1):50-55.

64. Keddis MT, Khanna S, Noheria A, Baddour LM, Pardi DS, Qian Q. Clostridium difficile infection in patients with chronic kidney disease. Mayo Clin Proc. 2012;87(11):1046-1053.

65. Cunney RJ, Magee C, McNamara E, Smyth EG, Walshe J. Clostridium difficile colitis associated with chronic renal failure. Nephrol Dial Transplant. 1998;13(11):2842-2846.

66. Eddi R, Malik MN, Shakov R, Baddoura WJ, Chandran C, Debari VA. Chronic kidney disease as a risk factor for Clostridium difficile infection. Nephrology (Carlton). 2010;15(4):471-475.

67. Khanna S, Keddis MT, Noheria A, Baddour LM, Pardi DS. Acute kidney injury is an independent marker of severity in Clostridium difficile infection: a nationwide survey. J Clin Gastroenterol. 2013;47(6): 481-484.

68. Schneeweiss S, Korzenik J, Solomon DH, Canning C, Lee J, Bressler B. Infliximab and other immunomodulating drugs in patients with inflammatory bowel disease and the risk of serious bacterial infections. Aliment Pharmacol Ther. 2009;30(3):253-264.

69. Das R, Feuerstadt P, Brandt LJ. Glucocorticoids are associated with increased risk of short-term mortality in hospitalized patients with Clostridium difficile-associated disease. Am J Gastroenterol. 2010;105(9):2040-2049.

70. Gellad ZF, Alexander BD, Liu JK, et al. Severity of Clostridium difficile-associated diarrhea in solid organ transplant patients. Transpl Infect Dis. 2007;9(4):276-280.

71. Kariv R, Navaneethan U, Venkatesh PG, Lopez R, Shen B. Impact of Clostridium difficile infection in patients with ulcerative colitis. J Crohns Colitis. 2011;5(1):34-40.

72. Ansari J, Choo B, Fernando I. Fatal Clostridium difficile infection associated with vinorelbine chemotherapy: case report and literature review. J Infect Chemother. 2010;16(3):210-212.

73. Sanchez TH, Brooks JT, Sullivan PS, et al. Bacterial diarrhea in persons with HIV infection, United States, 1992-2002. Clin Infect Dis. 2005;41(11):1621-1627.

74. Arango JI, Restrepo A, Schneider DL, et al. Incidence of Clostridium difficile-associated diarrhea before and after autologous peripheral blood stem cell transplantation for lymphoma and multiple myeloma. Bone Marrow Transplant. 2006;37(5):517-521.

75. Tomblyn M, Gordon L, Singhal S, et al. Rarity of toxigenic Clostridium difficile infections after hematopoietic stem cell transplantation: implications for symptomatic management of diarrhea. Bone Marrow Transplant. 2002;30(8):517-519.

76. Bobak D, Arfons LM, Creger RJ, Lazarus HM. Clostridium difficile-associated disease in human stem cell transplant recipients: coming epidemic or false alarm? Bone Marrow Transplant. 2008;42(11): 705-713.

77. Jillella AP, Ustun C, Robach E, et al. Infectious complications in patients receiving mobilization chemotherapy for autologous peripheral blood stem cell collection. J Hematother Stem Cell Res. 2003;12(2): 155-160. 
78. Alonso CD, Treadway SB, Hanna DB, et al. Epidemiology and outcomes of Clostridium difficile infections in hematopoietic stem cell transplant recipients. Clin Infect Dis. 2012;54(8):1053-1063.

79. Neofytos D, Kobayashi K, Alonso CD, et al. Epidemiology, risk factors, and outcomes of Clostridium difficile infection in kidney transplant recipients. Transpl Infect Dis. 2013;15(2):134-141.

80. Dubberke ER, Gerding DN, Classen D, et al. Strategies to prevent clostridium difficile infections in acute care hospitals. Infect Control Hosp Epidemiol. 2008;29 Suppl 1:S81-S92.

81. Shaughnessy MK, Micielli RL, DePestel DD, et al. Evaluation of hospital room assignment and acquisition of Clostridium difficile infection. Infect Control Hosp Epidemiol. 2011;32(3):201-206.

82. Dubberke ER, Reske KA, Noble-Wang J, et al. Prevalence of Clostridium difficile environmental contamination and strain variability in multiple health care facilities. Am J Infect Control. 2007;35(5): 315-318.

83. Kim KH, Fekety R, Batts DH, et al. Isolation of Clostridium difficile from the environment and contacts of patients with antibiotic-associated colitis. J Infect Dis. 1981;143(1):42-50.

84. Eyre DW, Cule ML, Wilson DJ, et al. Diverse sources of Clostridium difficile infection identified on whole-genome sequencing. $N$ Engl J Med. 2013;369(13):1195-1205.

85. Otten AM, Reid-Smith RJ, Fazil A, Weese JS. Disease transmission model for community-associated Clostridium difficile infection. Epidemiol Infect. 2010;138(6):907-914.

86. Bavishi C, Dupont HL. Systematic review: the use of proton pump inhibitors and increased susceptibility to enteric infection. Aliment Pharmacol Ther. 2011;34(11-12):1269-1281.

87. Ozaki E, Kato H, Kita H, et al. Clostridium difficile colonization in healthy adults: transient colonization and correlation with enterococcal colonization. J Med Microbiol. 2004;53 Pt 2:167-172.

88. Riggs MM, Sethi AK, Zabarsky TF, Eckstein EC, Jump RL, Donskey CJ. Asymptomatic carriers are a potential source for transmission of epidemic and nonepidemic Clostridium difficile strains among long-term care facility residents. Clin Infect Dis. 2007;45(8): 992-998.

89. Clabots CR, Johnson S, Olson MM, Peterson LR, Gerding DN. Acquisition of Clostridium difficile by hospitalized patients: evidence for colonized new admissions as a source of infection. J Infect Dis. 1992;166(3):561-567.

90. Kim JH, Toy D, Muder RR. Clostridium difficile infection in a longterm care facility: hospital-associated illness compared with long-term care-associated illness. Infect Control Hosp Epidemiol. 2011;32(7): 656-660.

91. Marwick CA, Yu N, Lockhart MC, et al. Community-associated Clostridium difficile infection among older people in Tayside, Scotland, is associated with antibiotic exposure and care home residence: cohort study with nested case-control. J Antimicrob Chemother. 2013;68(12): 2927-2933.

92. Stoesser N, Crook DW, Fung R, et al. Molecular epidemiology of Clostridium difficile strains in children compared with that of strains circulating in adults with Clostridium difficile-associated infection. J Clin Microbiol. 2011;49(11):3994-3996.

93. Rousseau C, Lemee L, Le Monnier A, Poilane I, Pons JL, Collignon A. Prevalence and diversity of Clostridium difficile strains in infants. J Med Microbiol. 2011;60 Pt 8:1112-1118.

94. Leffler DA, Lamont JT. Editorial: not so nosocomial anymore: the growing threat of community-acquired Clostridium difficile. Am J Gastroenterol. 2012;107(1):96-98.

95. Jury LA, Sitzlar B, Kundrapu S, et al. Outpatient healthcare settings and transmission of Clostridium difficile. PLoS One. 2013;8(7):e70175.

96. Sethi AK, Al-Nassir WN, Nerandzic MM, Bobulsky GS, Donskey CJ. Persistence of skin contamination and environmental shedding of Clostridium difficile during and after treatment of Clostridium difficile infection. Infect Control Hosp Epidemiol. 2010;31(1):21-27.

97. Weese JS. Clostridium difficile in food - innocent bystander or serious threat? Clin Microbiol Infect. 2010;16(1):3-10.
98. Jhung MA, Thompson AD, Killgore GE, et al. Toxinotype V Clostridium difficile in humans and food animals. Emerg Infect Dis. 2008;14(7):1039-1045.

99. Rupnik M. Is Clostridium difficile-associated infection a potentially zoonotic and foodborne disease? Clin Microbiol Infect. 2007;13(5): $457-459$.

100. Rodriguez-Palacios A, Reid-Smith RJ, Staempfli HR, Weese JS. Clostridium difficile survives minimal temperature recommended for cooking ground meats. Anaerobe. 2010;16(5):540-542.

101. Avbersek J, Janezic S, Pate M, et al. Diversity of Clostridium difficile in pigs and other animals in Slovenia. Anaerobe. 2009;15(6): $252-255$

102. Weese JS, Avery BP, Rousseau J, Reid-Smith RJ. Detection and enumeration of Clostridium difficile spores in retail beef and pork. Appl Environmen Microbiol. 2009;75(15):5009-5011.

103. Indra A, Lassnig $\mathrm{H}$, Baliko $\mathrm{N}$, et al. Clostridium difficile: a new zoonotic agent? Wien Klin Wochenschr. 2009;121(3-4):91-95.

104. Pirs T, Ocepek M, Rupnik M. Isolation of Clostridium difficile from food animals in Slovenia. J Med Microbiol. 2008;57 Pt 6:790-792.

105. Keel MK, Songer JG. The distribution and density of Clostridium difficile toxin receptors on the intestinal mucosa of neonatal pigs. Vet Pathol. 2007;44(6):814-822.

106. Rodriguez-Palacios A, Stampfli HR, Duffield T, et al. Clostridium difficile PCR ribotypes in calves, Canada. Emerg Infect Dis. 2006;12(11): 1730-1736.

107. Arroyo LG, Kruth SA, Willey BM, Staempfli HR, Low DE, Weese JS. PCR ribotyping of Clostridium difficile isolates originating from human and animal sources. J Med Microbiol. 2005;54 Pt 2: $163-166$

108. Gould LH, Limbago B. Clostridium difficile in food and domestic animals: a new foodborne pathogen? Clin Infect Dis. 2010;51(5): 577-582.

109. Songer JG, Trinh HT, Killgore GE, Thompson AD, McDonald LC, Limbago BM. Clostridium difficile in retail meat products, USA, 2007. Emerg Infect Dis. 2009;15(5):819-821.

110. Goorhuis A, Bakker D, Corver J, et al. Emergence of Clostridium difficile infection due to a new hypervirulent strain, polymerase chain reaction ribotype 078. Clin Infect Dis. 2008;47(9):1162-1170.

111. Bakker D, Corver J, Harmanus C, et al. Relatedness of human and animal Clostridium difficile PCR ribotype 078 isolates determined on the basis of multilocus variable-number tandem-repeat analysis and tetracycline resistance. J Clin Microbiol. 2010;48(10): 3744-3749.

112. Marsh JW. Counterpoint: is Clostridium difficile a food-borne disease? Anaerobe. 2013;21:62-63.

113. Riley TV, Thean S, Hool G, Golledge CL. First Australian isolation of epidemic Clostridium difficile PCR ribotype 027. Med J Aust. 2009;190(12):706-708.

114. Bacci S, St-Martin G, Olesen B, et al. Outbreak of Clostridium difficile 027 in North Zealand, Denmark, 2008-2009. Euro Surveill. 2009; 14(16). pii: 19183.

115. Pituch H, Bakker D, Kuijper E, et al. First isolation of Clostridium difficile PCR-ribotype 027/toxinotype III in Poland. Pol J Microbiol. 2008;57(3):267-268.

116. Notermans DW, van der Kooi TI, Goorhuis A, Debast SB, van Benthem BH, Kuijper EJ. [Epidemiology of Clostridium difficile PCR ribotype 027 in The Netherlands 2005-present and the emergence of other subtypes]. Ned Tijdschr Geneeskd. 2008;152(35):1937-1940. Dutch.

117. Goorhuis A, Van der Kooi T, Vaessen N, et al. Spread and epidemiology of Clostridium difficile polymerase chain reaction ribotype 027/toxinotype III in The Netherlands. Clin Infect Dis. 2007;45(6): 695-703.

118. Joseph R, Demeyer D, Vanrenterghem D, van den Berg R, Kuijper E, Delmee M. First isolation of Clostridium difficile PCR ribotype 027, toxinotype III in Belgium. Euro Surveill. 2005;10(10): E051020-E051024. 
119. Bauer MP, Notermans DW, van Benthem BH, et al. Clostridium difficile infection in Europe: a hospital-based survey. Lancet. 2011; 377(9759):63-73.

120. Hensgens MP, Goorhuis A, Notermans DW, van Benthem BH, Kuijper EJ. Decrease of hypervirulent Clostridium difficile PCR ribotype 027 in The Netherlands. Euro Surveill. 2009;14(45). pii: 19402

121. De Almeida MN, Heffernan H, Dervan A, et al. Severe Clostridium difficile infection in New Zealand associated with an emerging strain, PCR-ribotype 244. N Z Med J. 2013;126(1380):9-14.

122. Tagashira Y, Kato H, Senoh M, Nakamura A. Two cases of fulminant colitis due to binary toxin-positive Clostridium difficile that are not PCR ribotype 027 or type 078. J Med Microbiol. 2013;62 Pt 9: 1486-1489.

123. Bignardi GE, Settle C. Different ribotypes in community-acquired Clostridium difficile. J Hosp Infect. 2008;70(1):96-98.

124. Belmares J, Johnson S, Parada JP, et al. Molecular epidemiology of Clostridium difficile over the course of 10 years in a tertiary care hospital. Clin Infect Dis. 2009;49(8):1141-1147.

125. Killgore G, Thompson A, Johnson S, et al. Comparison of seven techniques for typing international epidemic strains of Clostridium difficile: restriction endonuclease analysis, pulsed-field gel electrophoresis, PCR-ribotyping, multilocus sequence typing, multilocus variable-number tandem-repeat analysis, amplified fragment length polymorphism, and surface layer protein A gene sequence typing. J Clin Microbiol. 2008;46(2):431-437.

126. Knetsch CW, Lawley TD, Hensgens MP, Corver J, Wilcox MW, Kuijper EJ. Current application and future perspectives of molecular typing methods to study Clostridium difficile infections. Euro Surveill. 2013;18(4):20381.

127. Marsh JW, O’Leary MM, Shutt KA, et al. Multilocus variablenumber tandem-repeat analysis for investigation of Clostridium difficile transmission in Hospitals. J Clin Microbiol. 2006;44(7): 2558-2566.

128. Eyre DW, Golubchik T, Gordon NC, et al. A pilot study of rapid benchtop sequencing of Staphylococcus aureus and Clostridium difficile for outbreak detection and surveillance. BMJ Open. 2012;2(3). pii: e001124.

129. Eyre DW, Fawley WN, Best EL, et al. Comparison of multilocus variable-number tandem-repeat analysis and whole-genome sequencing for investigation of Clostridium difficile transmission. J Clin Microbiol. 2013;51(12):4141-4149.
130. Walker AS, Eyre DW, Wyllie DH, et al. Relationship between bacterial strain type, host biomarkers, and mortality in Clostridium difficile infection. Clin Infect Dis. 2013;56(11):1589-1600.

131. Smits WK. Hype or hypervirulence: a reflection on problematic Clostridium difficile strains. Virulence. 2013;4(7):592-596.

132. Shin BM, Moon SJ, Kim YS, Shin WC, Yoo HM. Characterization of cases of Clostridium difficile infection (CDI) presenting at an emergency room: molecular and clinical features differentiate communityonset hospital-associated and community-associated CDI in a tertiary care hospital. J Clin Microbiol. 2011;49(6):2161-2165.

133. MacCannell DR, Louie TJ, Gregson DB, et al. Molecular analysis of Clostridium difficile PCR ribotype 027 isolates from Eastern and Western Canada. J Clin Microbiol. 2006;44(6):2147-2152.

134. Limbago BM, Long CM, Thompson AD, et al. Clostridium difficile strains from community-associated infections. $J$ Clin Microbiol. 2009;47(9):3004-3007.

135. Rupnik M. Heterogeneity of large clostridial toxins: importance of Clostridium difficile toxinotypes. FEMS Microbiol Rev. 2008;32(3): 541-555.

136. Bauer MP, Veenendaal D, Verhoef L, Bloembergen P, van Dissel JT, Kuijper EJ. Clinical and microbiological characteristics of communityonset Clostridium difficile infection in The Netherlands. Clin Microbiol Infect. 2009;15(12):1087-1092.

137. Miller M, Gravel D, Mulvey M, et al. Health care-associated Clostridium difficile infection in Canada: patient age and infecting strain type are highly predictive of severe outcome and mortality. Clin Infect Dis. 2010;50(2):194-201.

138. Henrich TJ, Krakower D, Bitton A, Yokoe DS. Clinical risk factors for severe Clostridium difficile-associated disease. Emerg Infect Dis. 2009;15(3):415-422.

139. Lamontagne F, Labbe AC, Haeck O, et al. Impact of emergency colectomy on survival of patients with fulminant Clostridium difficile colitis during an epidemic caused by a hypervirulent strain. Ann Surg. 2007;245(2):267-272.

140. Moshkowitz M, Ben-Baruch E, Kline Z, Shimoni Z, Niven M, KonikoffF. Risk factors for severity and relapse of pseudomembranous colitis in an elderly population. Colorectal Dis. 2007;9(2):173-177.

141. Khanna S, Pardi DS, Aronson SL, Kammer PP, Baddour LM. Outcomes in community-acquired Clostridium difficile infection. Aliment Pharmacol Ther. 2012;35(5):613-618.
Infection and Drug Resistance

\section{Publish your work in this journal}

Infection and Drug Resistance is an international, peer-reviewed openaccess journal that focuses on the optimal treatment of infection (bacterial, fungal and viral) and the development and institution of preventive strategies to minimize the development and spread of resistance. The journal is specifically concerned with the epidemiology of antibiotic

\section{Dovepress}

resistance and the mechanisms of resistance development and diffusion in both hospitals and the community. The manuscript management system is completely online and includes a very quick and fair peerreview system, which is all easy to use. Visit http://www.dovepress.com/ testimonials.php to read real quotes from published authors. 